\title{
Interaction Between Physics and Society
}

\author{
Position of Physics in Europe \\ Impact of Microprocessors on Society \\ Cultural Value of an Education in Physics
}

\author{
D. H. Parkinson, Malvern
}

As at EPS 4 in York, among the Plenary Lectures and Symposia on physics, there will be sessions at Istanbul, held under the auspices of the EPS Advisory Committee on Physics and Society (ACPS). The first on Monday will deal with "The Position of Physics in Europe" (Symposium 11a) and the second on Thursday with "The Impact of Microprocessors on Society" (Symposium 11b). In addition there will be a full session on Thursday evening on "The Cultural Value of an Education in Physics" (Symposium 11c).

Besides these activities within EPS 5, the ACPS is organizing a Seminar on 4-5 September in Istanbul on the "Problems of Physics in the Less Developed Countries of Europe", which is being actively supported by UNESCO in the form of grants to participants from the less-developed countries.

\section{The Position of Physics}

The discussion on the position of physics in a particular country or in Europe as a whole will cover topics such as: - its standing in the esteem of Society, its management and financing, its state of development as represented by contributions to the most active fields of research, and the number and quality of physicists and their employment.

One way to gauge the interest in such topics is to study a bibliography of publications dealing with, for example, the standing, financing and organisation of physics in individual countries. It is commonly said that physics as a subject is not /accorded the standing in society to which it is entitled, that it is under-financed and so on. One object of Symposium 11a is to attempt to bring a number of these aspects into proper focus for Europe as well as for individual countries.

Obviously there is a considerable unevenness in the state of development of physics in the different countries of Europe, a situation that is partly governed by their disparate sizes and economic and industrial development. If one accepts the present budgetry limitations in each country, one suspects that there are also great differences in the effectiveness with which resources are put to work, both in terms of pushing back the frontiers of physics and in applying known physics to practical problems. How such comparisons can be made and how useful they might be, should become clearer in the course of Symposium 11a.

\section{Microprocessors}

The electronics industry is based on physics, though not directly and solely. Microprocessors constitute the most important present development in electronics and are a direct product of the application of semiconductor physics and materials science. It is therefore apposite that attention in being given to the topic in "The Impact of Microprocessors on Society". This is a subject which has attracted much attention already. What is not fully appreciated at present is the full extent of the "silicon-chip revolution" and its consequences.

In any discussion one must have some idea of the technical changes that are in train and these seem almost limitless. There is no process involving calculation, recording, memorising, control or measurement in which a microprocessor cannot be incorporated. When it does so in conventional industry, it usually offers greater reliability and speed by the elimination of human operators. Instruments become more compact, robust and reliable. In addition, new and more complex measurements, processes, instruments, calculations and so on become possible. All technical fields in which electronics figures now are subject to dramatic change.

The impact of these changes on Society, particularly in industrialised nations, is going to be severe. There is no question that the application of these techniques in existing industry implies the use of fewer people to produce the same output. On the other hand, it can be argued that new industrial activities will ensue. Just what the net result will be finally, in terms of employment, is difficult to gauge. Many of the present industrial skills may disappear, but will they be replaced by others? In the past, technical innovations have been absorbed into the life of a nation (and vice-versa) but they nevertheless have been instruments of great change in the patterns of life, work and leisure. Those of the near future will be more significant than those of the past.

As a precursor of Symposium 11b, there will be a morning Plenary Lecture on the "Impact of Microelectronics on Society" which will set the scene in general terms. The afternoon Symposium will begin with an examination of the technical impact of microprocessors in electronics and its immediate consequences. This will be followed by contributions concerned with the problems of employment and retraining, and their implications in education, industrial relations and management, and in individual life styles.

The Symposium will end by examining some of the problems of personal life implicit in a microelectronics world: not simply material life styles, but the pursuits followed in leisure time, the security and privacy of personal records held in central information stores, the possibilities of fraud and so on. It has been said that physicists are so absorbed in their immediate problems that they neither know where they have come from nor where they are going. The interest expressed in these Symposia, as indicated by the preliminary registrations, shows that such a view is erroneous.

\section{An Education in Physics}

The third Symposium (11c) on "The Cultural Value of an Education in Physics" is in a sense a challenge to each of us to be conscious of what a general education in physics can do, particularly for those who are not going to become professional physicists. Clearly an important factor is the manner in which physics is taught, but this applies to any subject. The cultural value of the study of classical literature or Shakespeare, is said to be largely due to the insights gained on human nature, besides the instruction received on the ways of expression through writing.

Physics can be taught so as to give a good "overview" of Nature ranging from the scale and workings of the Universe, on the one hand, through the intricacies of the solid state to atomic and nuclear physics on the other. An important outcome can then be a deeper appreciation of man's position in, and his relation to, Nature as a whole. In this sense an education in physics can be of great cultural value. Whereas it may not teach directly the more subtle nuances of human nature, it can at least inculcate a degree of humility in the student, as well as an understanding of the very critical conditions needed for life and the limited resources that we have at our disposal. This Symposium also seems to have attracted great interest as judged from the preliminary registrations. 

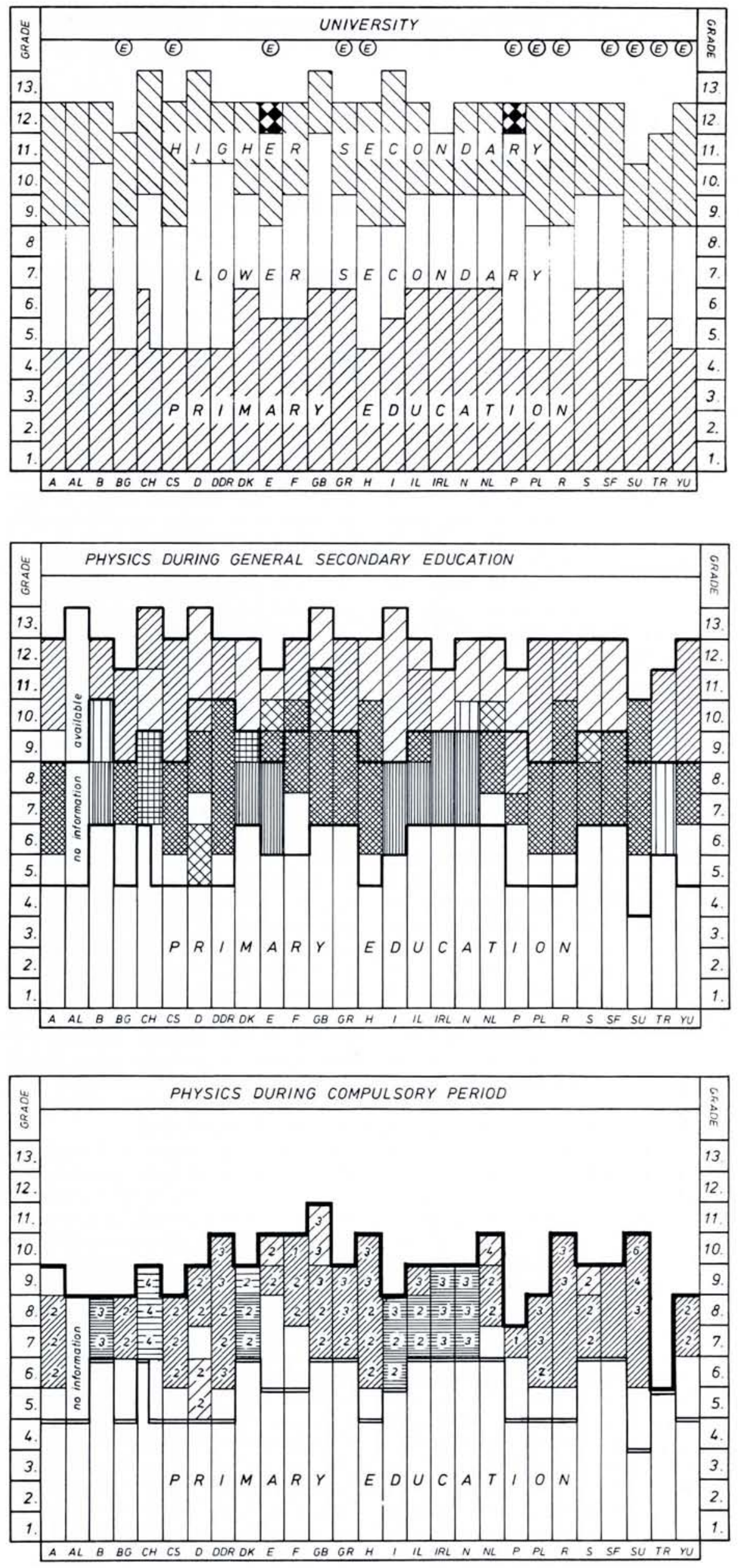

(E) Entrance examination

Orientation course preceeding universitary education

Fig. 2 - Primary and secondary education in different European countries.

稀 $\begin{aligned} & \text { Compulsory physics for all pupils (com- } \\ & \text { pulsory period) }\end{aligned}$

Compulsory physics for some pupils (compulsory period)

Compulsory physics for all pupils (volunteer period)

$\square$ Optional physics (volunteer period)

Compulsory science for all pupils (compulsory period)

Compulsory science for some pupils (compulsory period)

Compulsory science for all pupils (volunteer period)

Fig. 3 - Physics during secondary education. Compulsory/Optional Periods.

US Compulsory physics for all pupils

$\square$ Compulsory physics for some pupils

Compulsory science for all pupils

$\Xi$ Compulsory science for some pupils

Fig. 4 - Physics lessons/week in different grades. 